International

Medical Society

http://imedicalsociety.org

\title{
Post-Stroke Sexual Dysfunction: Obstacles to Promote a Comprehensive Care

\section{Abstract}

Stroke is considered the fifth leading cause of death worldwide and the leading cause of sequelae in the affected individuals. Among the major shortcomings, there are changes in speech, strength, sensation, cognition and sexuality, causing serious implications for the quality of life of affected patients. In this ambience, the work of a multidisciplinary team is essential to understand the needs and peculiarities in individual treatment and care post-stroke, aiming to rehabilitate patients for performing instrumental activities of daily living. However, several studies indicate a deficiency of the multidisciplinary team to address sexuality, not revealed by theme or approach for patient dissatisfaction on how this issue is managed. This happens because of the absence of a proper scale to address sexuality in the context of stroke, revealing the need to develop and validate an instrument that specifically applies to patients with sexual dysfunction post-stroke.

Stroke is characterized by the decrease or complete cessation of cerebral blood supply [1]. In 2010, worldwide prevalence of this disease was 33 million, with 16.9 million people having a first stroke. This condition kills nearly 129,000 people a year, being considered it is the no. 5 cause of death and the leading cause of adult disability [2]. In Brazil, 160,621 hospitalizations were recorded by cerebrovascular diseases in 2009, according to data in the public domain of the Unified Health System. The mortality rate was 51.8 every group of 100,000 inhabitants [3].

The sequelae include dysphasia, hemiparesis, changes in cognition, and changes in the ability to express emotions, all of which may impact the ability of a stroke survivor to perform activities of daily living, including sexual activity [4]. In this sense, neurological disorders are frequently responsible for sexual disorders. Their impact can be ma-
Ivana Rios Rodrigues ${ }^{1,2}$, Messias Silvano da Silva Filho ${ }^{3}$, José Antônio de Lima Neto ${ }^{3}$, Modesto Leite Rolim Neto ${ }^{3,4}$

1 State University of Ceará. FortalezaCeará, Brazil.

2 General Hospital of Fortaleza. Stroke Unit. Fortaleza-Ceará, Brazil.

3 Estacio Faculty of Medicine of Juazeiro do Norte-Ceará. Fortaleza-Ceará, Brazil.

4 Federal University of Cariri. FortalezaCeará, Brazil.

\section{Contact information:}

Ivana Rios Rodrigues.

Address: Marechal Deodoro Street 55, apartment 103. Fortaleza-Ceará, Brazil. Tel: +55085987626220 .

झ ivana_rius@hotmail.com

Keywords

Stroke; Sexuality; Sexual dysfunction 
jor and could rank first in the concerns of patients with neurological handicap [5]. Consequently impaired sexual activity is not uncommon after ischaemic stroke [6].

Post-stroke impaired sexual activity encompasses sexual dysfunction [7]. Common sexual problems include difficulty with erection and ejaculation in men, vaginal lubrication issues for women, and orgasmic problems for both men and women [8]. Therefore, erectile dysfunction is common sequelae after stroke [9].

So, health professionals should provide opportunities for women and men to express their emotions following a stroke and should initiate the topic of post-stroke sexuality [10]. In this way, it is important to use assessment tools which can be easily used in practical configuration and can provide a starting point for sexual counseling and pointers to address sexual 4 and issues, in addition, may indicate a desire for additional information and advice from health professionals [11].

Recent guidelines published by the American Heart Association included a recommendation that patient and partner counseling regarding sexual activity be provided after a cardiovascular disease [12]. It has been seen that a primary concern for stroke survivors is maximizing their quality of life [13].

Most stroke survivors identify sexuality as an important issue in their post-stroke rehabilitation [11]. It is necessary that health professionals know that individuals with stroke are not satisfied with how the rehabilitation community addresses sexual dysfunction and have identified several issues with their post-stroke rehabilitation care [14]. Thus, it is important to know that the lack of consensus about the particulars of addressing sexuality coupled with evidence that health professionals feel embarrassed and unprepared for these discussions presents challenges to meeting the need for education about post-stroke sexuality [10].

More research should focus on the individual sexual needs of men and women after stroke due

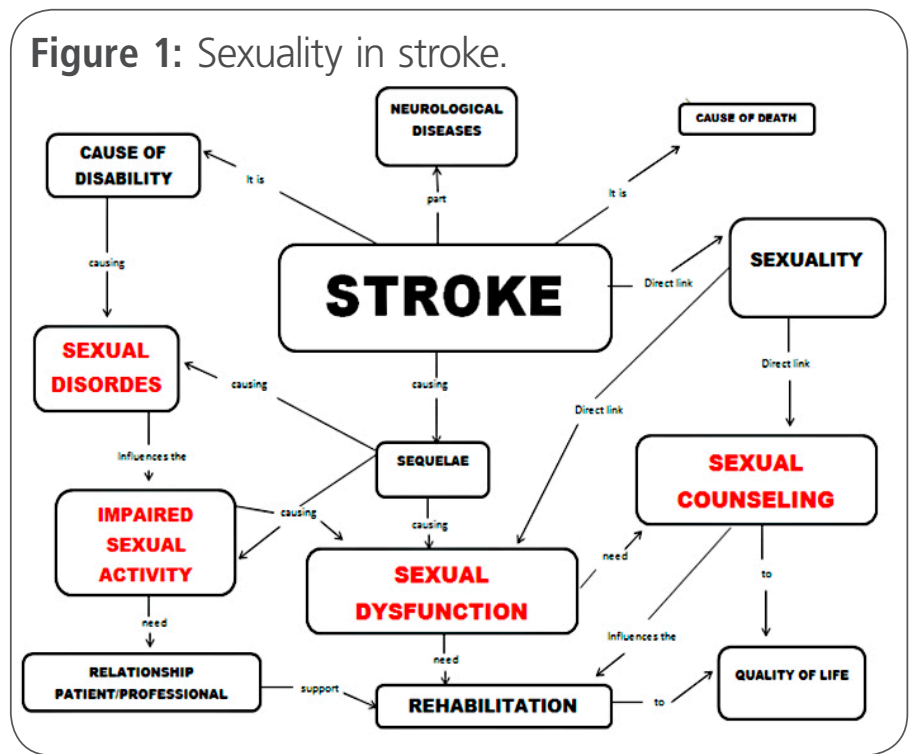

to the lack of knowledge on this topic and future research should investigate longitudinal changes in sexual activity after stroke [15].

It has been shown that stroke is a disease responsible for causing various disabilities, leaving sequels, among them the one involving sexuality, giving emphasis to sexual dysfunction. This condition is very present in the lives of patients affected by stroke, because they have impaired sexual activity, which can interfere with their quality of life. It is essential that health professionals are trained in dealing with people affected by sexual dysfunction post-stroke by providing adequate support, especially for young patients, in order to present an effective rehabilitation (Figure 1).

Few studies have focused on the number of patients receiving counseling sex, and less still have examined the quality and effectiveness of sexual advice after a stroke. Research shows that health professionals are still unprepared to deal with post stroke sexual dysfunction. Thus, it is necessary that the multidisciplinary team understands the peculiarities and needs of these patients in order to promote the rehabilitation and support for these patients return to perform instrumental activities of daily living.

Future research should focus on patients and their partners, as well as health professionals, so 
that both can understand the sexual concerns and develop strategies to ensure that sexual counseling should be a routine practice. This is because studies reveal dissatisfaction of patients as the form of management and approach to this topic. This is due, among other variables, the lack of an appropriate scale to address sexuality in the context of stroke, revealing the need to construct and validate an instrument that specifically applies to patients with post-stroke sexual dysfunction.

\section{References}

1. Stroke association [Internet] American Heart Association: American Stroke Association; 2015. Available in: http://www. strokeassociation.org/STROKEORG/AboutStroke/About-Stroke UCM 308529 SubHomePage.jsp

2. Roger VL, et al. Heart disease and stroke statistics - 2012 update: a report from the American Heart Association. Circulation. 2012; 125: e2-220.

3. Ministry of Health of Brazil [Internet] Hospital Information System SUS - SIH / SUS IBGE: demographic base; 2010. Available in: http://www2.datasus.gov.br/DATASUS/index.php?area=02.

4. Steinke $E E$, et al. Sexual counselling for individuals with cardiovascular disease and their partners: a consensus document from the American Heart Association and the ESC Council on Cardiovascular Nursing and Allied Professions (CCNAP). Eur Heart J. 2013 Nov; 34(41): 3217-35.

5. Denys P, Soler JM, Giuliano F. Sexuality of men with neurologic disorders. Prog Urol. 2013 Jul; 23(9): 712-7.

6. Bugnicourt JM, Hamy O, Canaple S, Lamy C, Legrand C. Impaired sexual activity in young ischaemic stroke patients: an observational study. Eur J Neurol. 2014; 21(1): 140-6.

7. Calabró RS, Gervasi G, Bramanti P. Male sexual disorders following stroke: an overview. Int J Neurosci 2011; 121: 598604.

8. Thompson SB, Walker L. Sexual dysfunction after stroke: underestimating the importance of psychological and physical issues. Webmed Central Physical Medicine. 2011.
9. Tibaek $S$, et al. The effect of pelvic floor muscle training on sexual function in men with lower urinary tract symptoms after stroke. Top Stroke Rehabil. 2015 Jun; 22(3): 185-93.

10. Beal CC, Millenbruch J. A qualitative case study of poststroke sexuality in a woman of childbearing age. J Obstet Gynecol Neonatal Nurs. 2015 Mar-Apr; 44(2): 228-35.

11. Stein J, Hillinger M, Clancy C, Bishop L. Sexuality after stroke: patient counseling preferences. Disabil Rehabil. 2013 Oct; 35(21): 1842-7.

12. Levine GN, et al. Sexual activity and cardiovascular disease: a scientific statement from the American Heart Association. Circulation. 2012; 125: 1058-72.

13. Hamam N, McCluskey A, Cooper Robbins S. Sex after stroke: a content analysis of printable educational materials available online. Int J Stroke. 2013 Oct; 8(7): 518-28.

14. Schmitz MA, Finkelstein M. Perspectives on poststroke sexual issues and rehabilitation needs. Topics in Stroke Rehabilitation. 2010; 17: 204-13.

15. Seymour LM, Wolf TJ. Participation changes in sexual functioning after mild stroke. OTJR (Thorofare N J). 2014 Spring; 34(2): 7280.

\section{Publish in International Archives of Medicine}

International Archives of Medicine is an open access journal publishing articles encompassing all aspects of medical science and clinical practice. IAM is considered a megajournal with independent sections on all areas of medicine. IAM is a really international journal with authors and board members from all around the world. The journal is widely indexed and classified Q1 in category Medicine. 